\title{
Application in the Training of Automatic Weather Station Based on Web3D Technology
}

\author{
http://dx.doi.org/10.3991/ijet.v10i4.4630 \\ Rui Yang, Wenjie Fan, Jingrong Sun \\ China Meteorological Administration Training Centre, Beijing, P.R. China
}

\begin{abstract}
Automatic weather station, one of the most significant observation instruments in China, has several particular characteristics, including precise parts, complex structure and various failures. Traditional training mode always relies on physical instruments which need large amounts of investment with long update cycle. During process of training, it is subject to making damage to instruments and trainees, which leads to ineffective even terminated training. Therefore, one new training mode is badly in need. Based on Web3D technology, this paper proposes one feasible virtual training application which takes into account particular characteristics of training for automatic weather station. It also describes an overall training plan, technology architecture, major module design and detailed implementation. This application has filled the blank of virtual Web3D training for automatic weather station, and opened up one new training approach. Also, the application scope of Web3D technology has been extended, especially into virtual training of specialized instruments.
\end{abstract}

Index Terms-Automatic weather station, Meteorological observation services, Virtual training, Web3D.

\section{INTRODUCTION}

Automatic weather station [1-3], an important part of China meteorological observation services, generally consists of sensors, data collectors, computers, display devices, print devices, power supply and etc. It is characterized by automatic acquisition, processing, storage and transmission of various essential meteorological data. There is a large population of professionals supporting its routine operations for nearly one decade. In pace with the development of meteorological observation services, automatic weather station is constantly being upgraded to obtain better automation and more accurate data. China Meteorological Administration also sets its development goals to enhance technical support for observation equipment by improving the professionals' relevant abilities, especially with regard to their operational ability which directly influences on observational data accuracy and observation system stability. It requires professional staff to understand intensively and master those relevant knowledge points involving operational principles, technical indicators, installation, maintenance, and troubleshooting. Traditional training mode always depends on physical instruments which require a heavy investment with long update cycle. During process of training, it is subject to making damage to instruments and trainees, which may results in ineffective even terminated training. Thus, traditional training has issues to meet the sharply growing demand for training because of restrictions on funds, sites and trainers. In other words, one new training mode is badly in need to satisfy requirement of quickly organized large- scale training.

Web3D [4-6], a combination of network and virtual reality technology [7-9], does well in creating a living and interactive virtual environment for users. It has advantages of network base, strong sense of interaction and low cost whereby it has extensively applied in the training of many industries[10-13], for example petroleum, automobile, architecture, geology and etc. This paper focuses on Web3D technology and its application in the training of automatic weather station. It is the first time that Web3D technology has been introduced into the training of meteorological observation services. As a completely updated training mode, Web3D training has made an active exploration to obtain high quality and efficient training of precision instruments just like automatic weather station.

\section{WeB3D TEChNOLOGY}

As the internet and virtual reality technology developed, Web3D technology was brought into being. It not only carries on characteristics of Web, but also takes all advantages of virtual reality technology such as reality, immersion, interactivity and imagination. Web3D technology derives from early VRML and develops into latest popular Unity3D, Virtools and Quest3D. Based on these technologies, users can experience $3 \mathrm{D}$ virtual interactions only by an access to URL through the browser. Because of its technical superiority, Web3D is just suitable for training. Compared with traditional training, Web3D training has its unique advantages as follows.

\section{A. Vivid training content}

Trainees can make a series of interactions in $3 \mathrm{D}$ virtual scene to enjoy a rich sense of reality. Different from traditional training, Web3D training does not have any difficulty in hardly explained training content, for example internal structure or operational principles of instruments, through three-dimensional perspective and simulation.

\section{B. Flexible training task}

For various training needs, trainers can flexibly choose and organize existing knowledge points to build their training tasks in the virtual environment. These tasks can be edited, updated and reorganized freely. Thanks to Web3D's network feature, training is no longer limited to particular time and places, which have greatly extended the scope of training.

\section{Low training cost}

The cost of Web3D training has been sharply reduced by saving rent for classrooms, payment of salary, equipment purchase and maintenance. 


\section{Safe training environment}

Trainees can exercise repeatedly in the Web3D virtual environment, not worried about harms caused by incorrect operations of instruments. The safe exercise environment helps trainees to inspire more interest and deeper understanding of training content, which results in better training effects.

\section{TRAINING OF AUTOMATIC WEATHER STATION IN CHINA}

Training of automatic weather station has a strong characteristic of practice. Trainees are asked to link knowledge and theory with actual operations. They gain guidance from theory on actual operations, and obtain better understanding of theory through practice. The cognitive loop of theory and practice aims trainees in making continuous and incremental improvements on their practical ability. Nowadays, the traditional mode is still the main approach of training for supporting automatic weather station. In the traditional one, theories are explained mainly by a combination of oral interpretation and power point presentation. Despite the multimedia method, the traditional training is still limited to texts, pictures and videos. Trainees merely take their passive watch which lacks adequate active participation and interaction. It is hard for them to master those invisible theories accurately and intensively, for example internal current flow. Also, guidance on actual operations is offered by mock-up show and oral explanation. One-to-one training is an effective way for actual operations. However, it is barely possible to organize plenty of one-to-one training since limited trainers, instruments and funds. The traditional mode is unable to meet sharply growing training demand for automatic weather station because of rapid technological advance and massive supporting professionals.

\section{OVERALL TRAINING PLAN AND TECHNOLOGY ARCHITECTURE BASED ON WEB3D}

\section{A. Overall training plan}

Web3D technology has been introduced into the training of automatic weather station on account of its technical advantages. In the virtual environment, a full-size simulation of precision instruments is made to create an immersive and convincing virtual reality for trainees. Compared to the traditional one, Web3D training significantly enhances its training efficiency and effectiveness as discussed in Section 6. Those hardly interpreted knowledge points, such as internal structure and operational principles of instruments, now are the highlight of Web3D training. Also, the main characteristics of instruments are exactly reproduced, involving complicated structure, precise components and various failures. A large number of failures with high frequency are shown in the realistic simulation as case studies. Web3D training has solved the problem in visualization and interactivity which troubled traditional training for many years. By full use of its technical strengths, Web3D training does well in capacity-building as below.

\section{Spatial imagination}

It is critical to set up the core concept of space for follow-up operational training. Trainees are unable to position parts of instrument accurately unless they master basic spatial data, including 3D structure, hierarchical relations, etc. After that, trainees are able to make correct operations of instruments, namely assembly, disassembly, maintenance and troubleshooting. Visual simulation of invisible principles, such as circuitry, helps trainees to deepen understanding. It also shows how one single part works and how parts react with the whole.

2. Knowledge migration

It is well-known that knowledge is always an idea remaining in the brain without any actual effect. When it is used into practice, it gives guidance on how to deal with actual situations. That is the training objective of automatic weather station to assist trainees in transferring their knowledge points to practical operations. In the Web3D environment, procedure in text and animation comply with operations of virtual instruments. The 3D prompt message highlights the correct position and operation step on the virtual model by keeping flashing. That helps trainees to put boring knowledge points into vivid hands-on operations, which greatly improve their practical operations.

3. Classification and summary

Because of various actual situations of instruments, it is important for trainees to correctly analyze and promptly cope with emergencies in the practical work. That needs them to build their strong classification and summary capacity to control various situations. By full use of its IT features, Web3D training provides trainees with repeated exercises for a certain knowledge point by a large number of cases. These cases are created on the basis of massive meteorological data stored in the database, and chosen randomly for trainees to help them comprehend and master typical solutions.

\section{B. Technology architecture}

After an analysis and comparison of various Web3D tools, Unity3D and .Net framework have been chosen as the technical architecture. While Untiy3D is rich in resources and easy to develop, it is just suitable for our IIS server with the excellent compatibility of .Net framework. In design, Web3D technical strengths, especially in network transmission, are fully utilized to obtain good simulation results and sharply reduced bandwidth by file compression and upload in batches. During implementation, Software named 3DMax and Maya is used for modeling, and models already built are imported into Unity3D platform to add logic driver. Then HTML and CSS are applied in the front-end design of web pages. Finally, data transmission and sharing between web pages and 3D virtual environment is achieved by using Java script. In the database design, basic material information is stored as resource metadata in files on the hard disk, including audio and video files, 3D model files and texture files. These files are associated with property sheets in the basic information database by XML file index. Basic information of instruments is stored as fields and properties in data tables of basic information database. Then structure relation tables and operation monitoring tables are created on the basis of that basic information. Logic data, such as operating procedure and methods, is divided into several groups in accordance with basic operations involving installation, maintenance and troubleshooting. Each group creates its own fields and properties in the operation rule data table. The system architecture is shown in Fig. 1. 


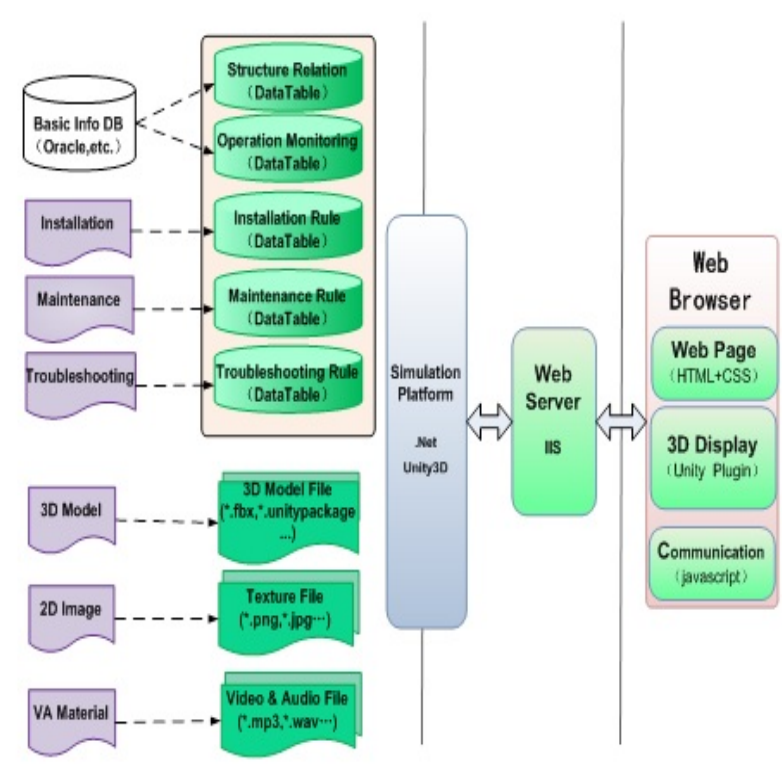

Figure 1. Overall system architecture

\section{WEB3D VIRTUAL TRAINING DESIGN}

Web3D training of precision instruments, just like automatic weather station, has massive knowledge points which badly need a reasonable organization to cover all points and conveniently to learn. So it has to be divided into several units relatively independent from each other, avoiding omissions and duplication. These independent training units are more suitable for large scale online training because of distributed access demands for server.

After summarizing training characteristics of automatic weather station, its Web3D application is designed in details by five units, involving structure and operational principles, operation monitoring, installation, maintenance and troubleshooting. These parts present progressive relationship. Trainees have to comprehend structure and operational principles of instruments before accurately monitoring them. According to a certain status of instruments, trainees are asked to make proper operations, such as installation, maintenance and troubleshooting. In addition, each unit has its unique training features in need of different virtual training methods which are classified into three categories discussed below.

\section{A. Principle demonstration}

This training method is designed for structure and operational principles mainly by explanations and demonstrations. Some important knowledge points hardly interpreted on the books are simulated through 3D animation and anatomy. For example, internal components and current trends are simulated to clearly show internal structure and correlation of components. 3D animation highlights key knowledge points hardly explained, accompany with caption. The operational principles of wind sensors and rain sensors are respectively simulated as shown in Fig. 2.

\section{B. Recognition and analysis}

This training method designed for operation monitoring emphases on how to recognize abnormal situations of instruments and how to analyze the causes. Various

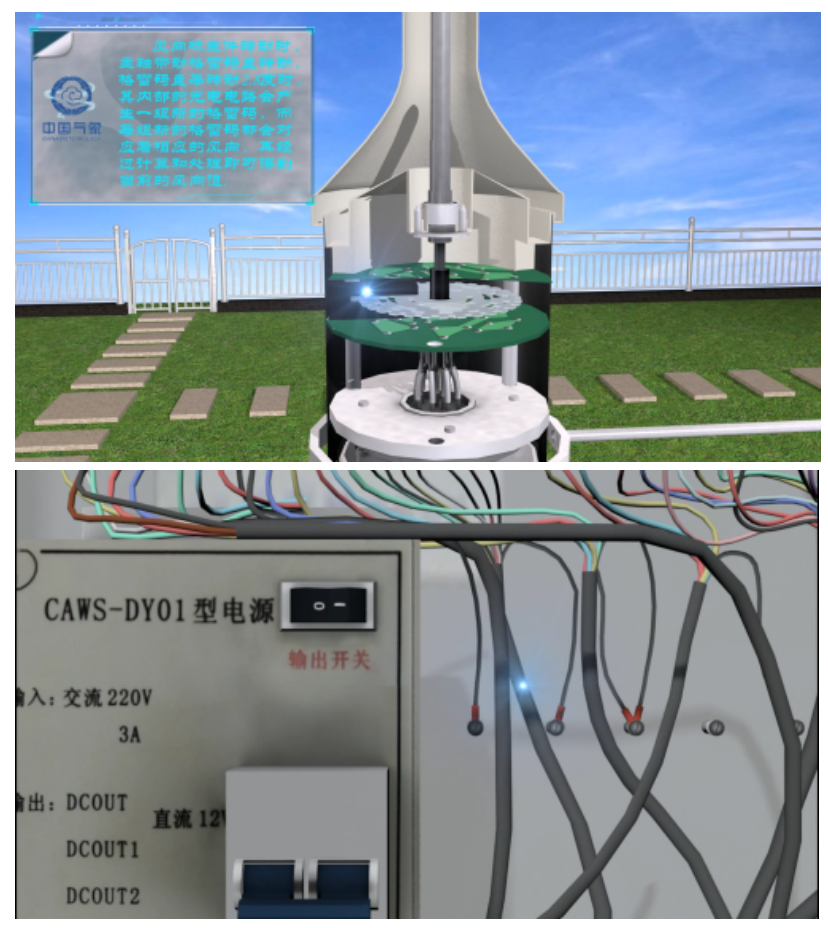

Figure 2. (a) Operational principles of wind sensors
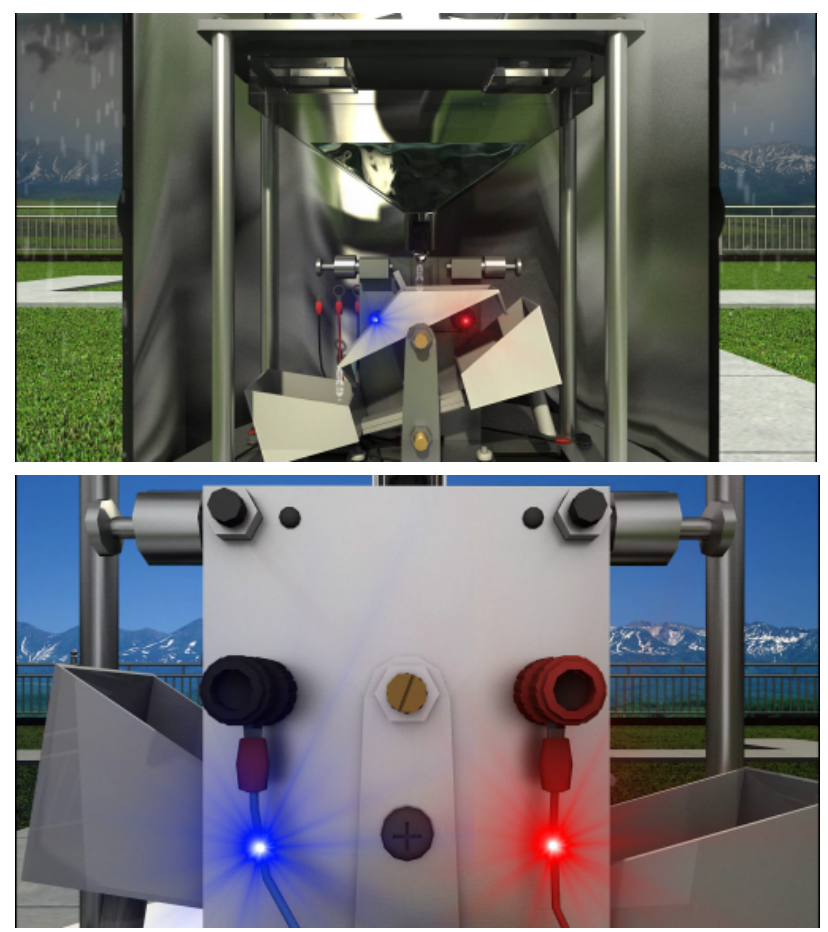

Figure 2. (b) Operational principles of rain sensors

weather conditions are simulated to reproduce actual working environment of instruments. Under different weather conditions, different operation status of instruments is also simulated accordingly. Trainees are required to make proper choices to determine which parameters have to be monitored by ticking appropriate check boxes. Operation monitoring interface of net radiation sensor is shown in Fig. 3. 
PAPER

Application in the Training of Automatic Weather Station Based on Web3D Technology

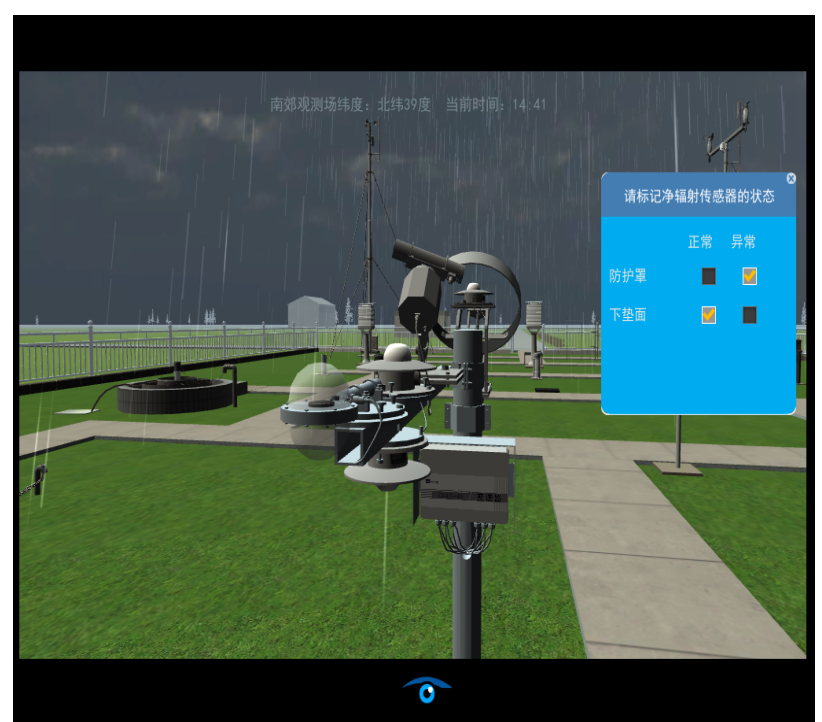

Figure 3. Operation monitoring interface of net radiation sensor

\section{Interaction}

This training method focuses on realistic simulation of interactions between trainees and virtual instruments, which adopts mouse actions and keyboard to imitate manual operations, such as using tools, picking up components, etc. Through interactions, trainees gradually enhance their capacities of knowledge migration and summary. Referring to operation characteristics, interactions are sorted into three subcategories, namely installation, maintenance and troubleshooting.

\section{Installation}

Installation is the most essential operation of automatic weather station, fundamental to other operations just like maintenance and troubleshooting. The simulation of this operation emphasizes correct operational procedure and proper installation approach of components. The first step starts from parts library designed to contain all randomly placed components. Trainees have to choose correct components from the library, and then assembly them in order by proper virtual actions. When referring to installation approaches, diverse virtual actions are elaborately designed to imitate each type of installation approach in details. For instance, virtual horizontal screws are adjusted to balance virtual spirit bubble, and virtual buttons are pushed down to run virtual motors. Virtual dials are aligned to calibrate longitude and latitude. In addition, there are several careful designs to help trainees to build their own knowledge system and knowledge migration capacity. For instance, the operation advices, found on the right of user interface, are highlighted as operation process to the appropriate steps. Details are shown in Fig. 4.

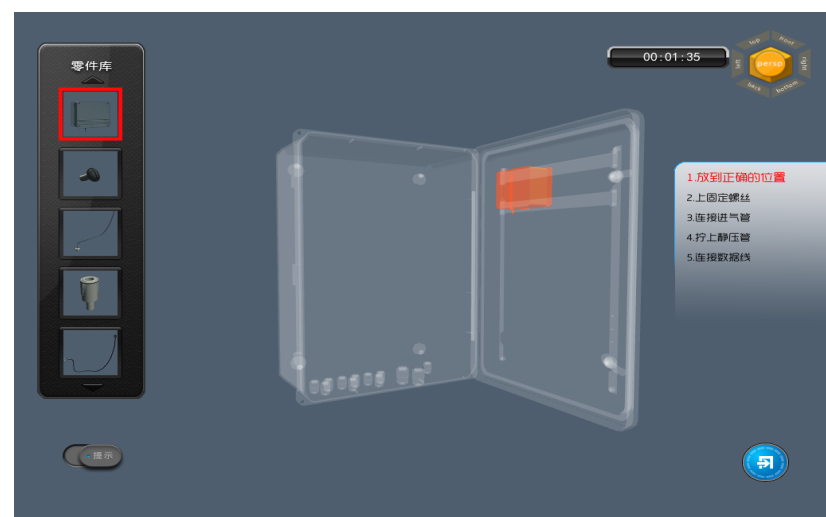

Figure 4. (a) Installation of atmospheric pressure sensor

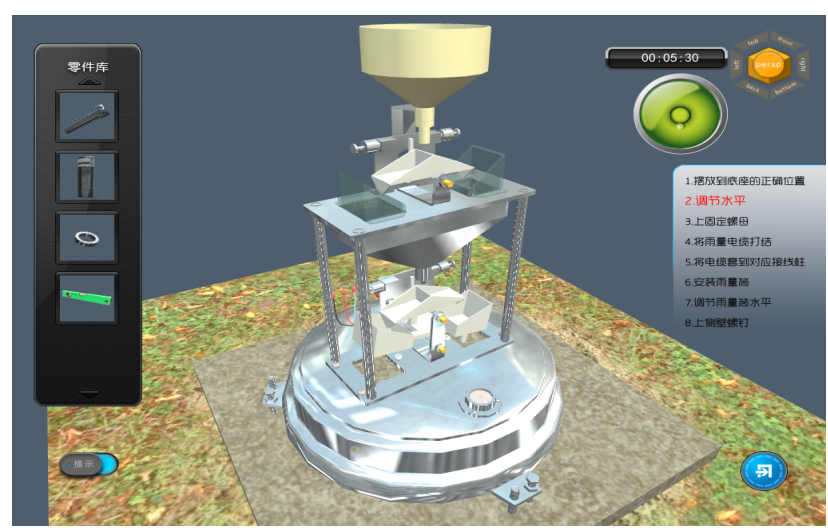

Figure 4. (b) Installation of triple rain gauge sensor

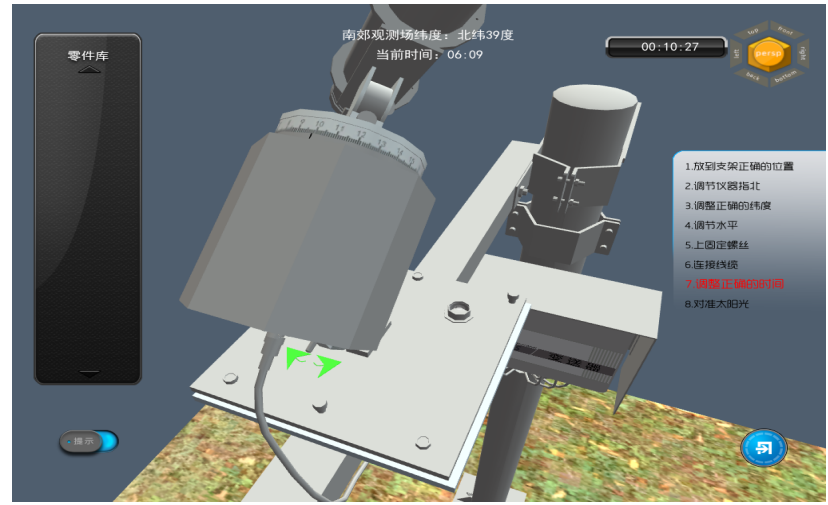

Figure 4. (c) Installation of direct radiometer

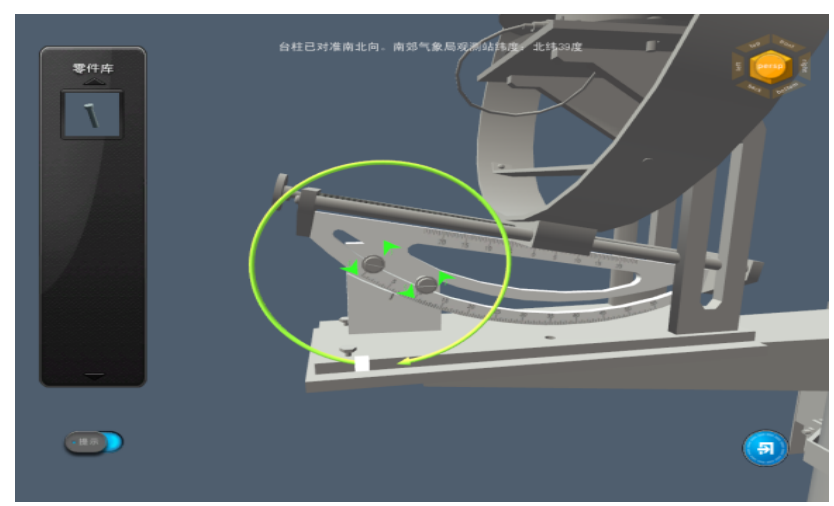

Figure 4. (d) Installation of scattered radiometer 
PAPER

Application in the Training of Automatic WeAther Station Based on Web3D Technology

\section{Maintenance}

For automatic weather station it is unavoidable to be ageing and decayed due to exposure outside all the year around. Usually, one leaf lightly covering the instrument may influence on the accuracy of collected data. Therefore, maintenance is an essential operation with meticulous care. This operation puts its emphasis on simulation of various detail maintenances. It refers to many daily operations such as removal, replacement and adjustment. Four widely used operations are shown in Fig. 5, including wiping the thermometer screen, clearing water filter mesh, replacing deformed weather vanes, and adjusting liquid height of evaporating dish.

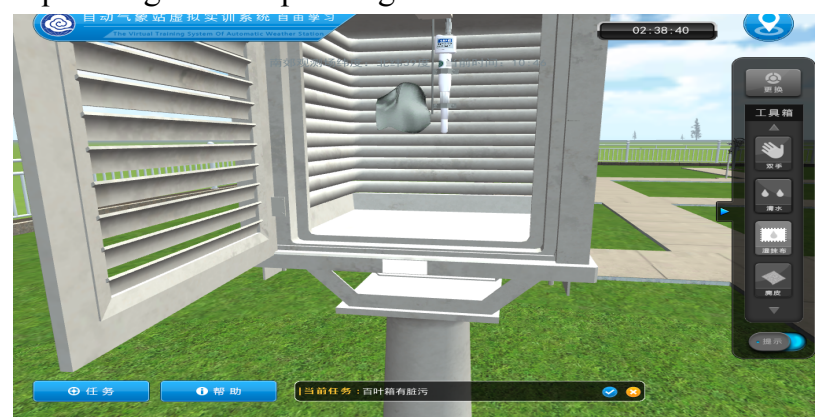

Figure 5. (a) Wiping the thermometer screen

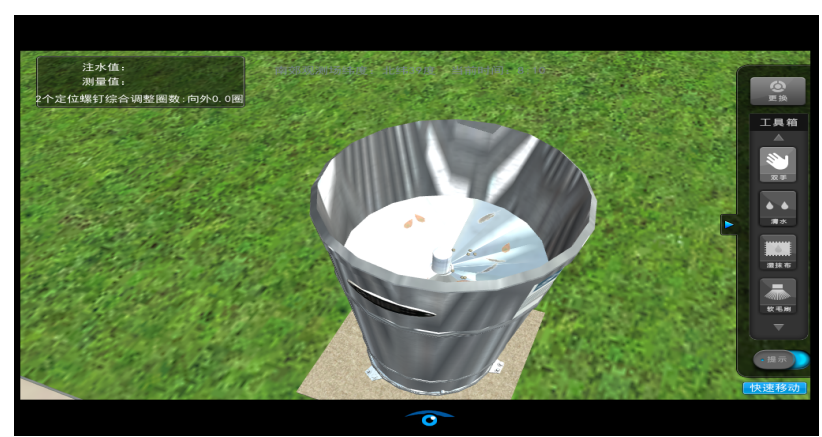

Figure 5. (b) Clearing water filter mesh

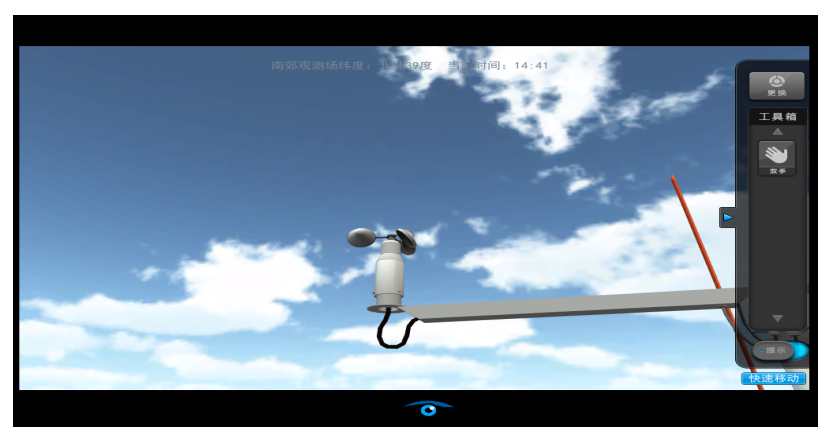

Figure 5. (c) Replacing deformed weather vanes

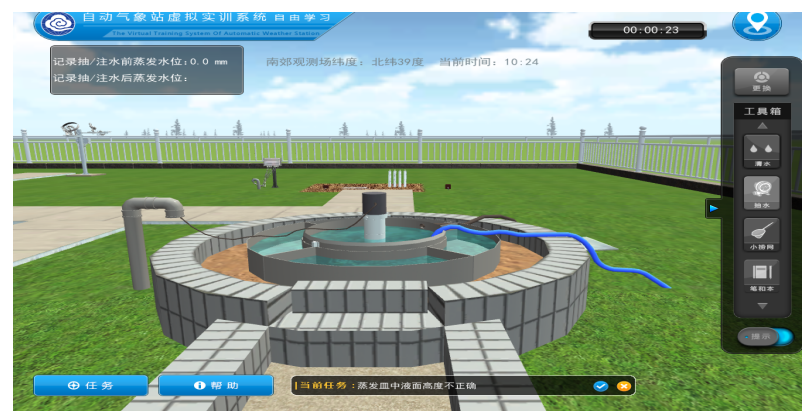

Figure 5. (d) Adjusting liquid height of evaporating dish

\section{Troubleshooting}

As mentioned above, instruments of automatic weather station has complex structure, high automation and close connection between components. Any partial failure may affect overall operation of instrument. The training objective for trainees is to build their classification and summary capacity to deal with diverse and ever-changing failures. First, failures are classified into several categories, for example power failure, cable failure, lightening protection device failure, etc. Each category is broken down into detailed fault spots. Then each fault spot defines its fault value range and relations with other spots. Simulation of various ever-changing monitoring data makes an exact reproduction of diverse failure symptoms. Besides, some widely used measuring apparatuses are simulated in details, for example multi-meter. Its gears, measuring range and operating procedure are carefully simulated for interactive measurements involving voltage, current, resistance, etc. That helps trainees greatly improve their operational ability as shown in Fig. 6.
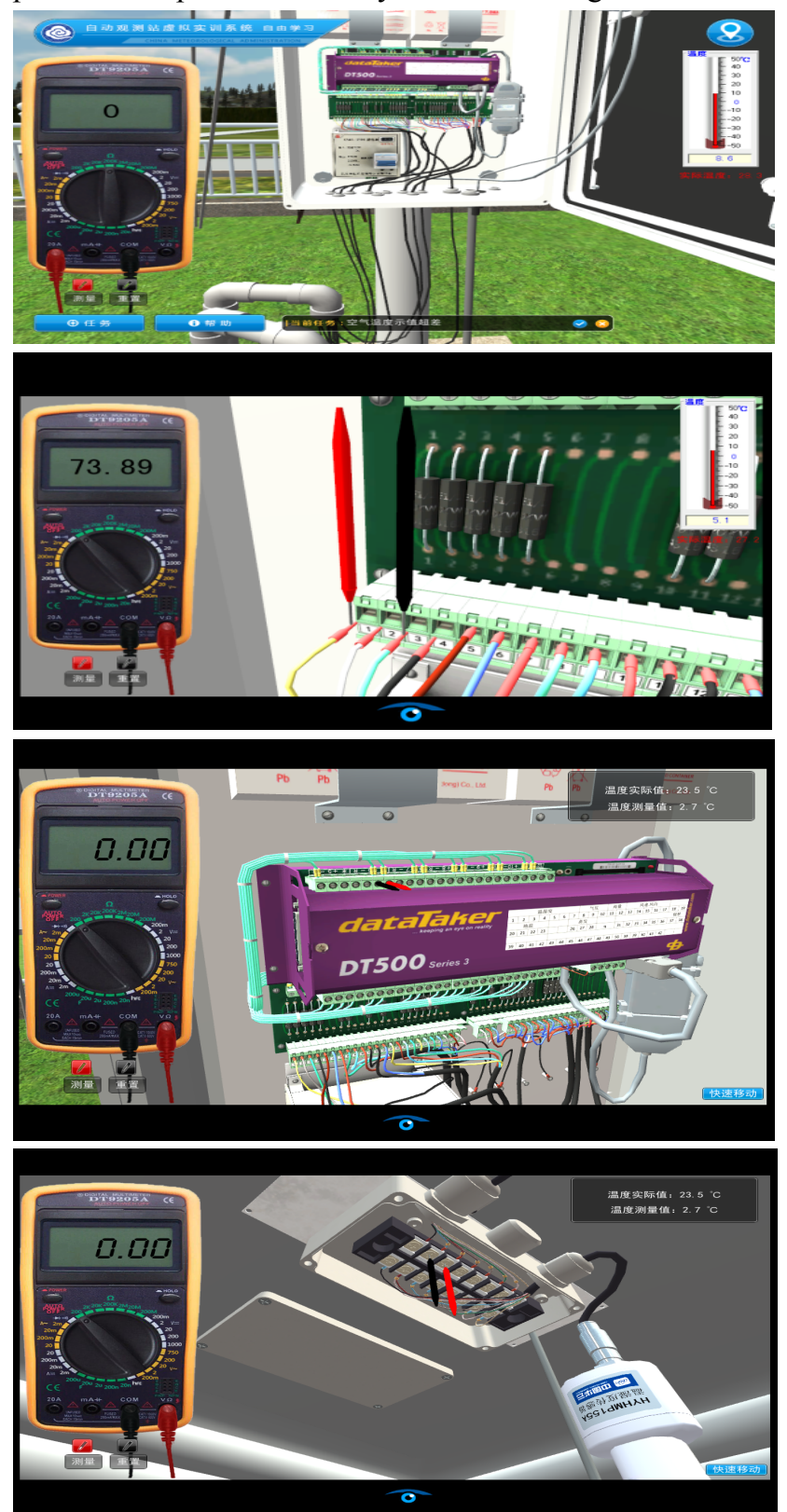

Figure 6. Troubleshooting of air temperature indication error 


\section{EXPERIMENTAL EVALUATION}

An experimental evaluation was conducted to investigate the effectiveness of Web3D training. Some feedback and reaction of trainees was collected by questionnaire, interview and course forum. Quantitative analysis based on data from pretest and posttest. Two training classes were selected randomly from china meteorological observer training class at Beijing. One consisting of 52 trainees acted as experimental group, and the other of 48 trainees acted as control group. The experiment lasted for 10 days, 2 hours a day. During the experiment, the experimental group introduced Web3D application into training activities, and trainers did not plan to get involved unless trainees asked for help. The control group still adopted traditional training mode.

Since there were differences of sample size and trainees' background, this experiment adopted analysis of covariance (ANCOVA) to investigate the influences of Web3D training on experimental results. The scores of pretest and posttest were recorded and analyzed by statistic software SPSS. The average and standard deviation of test scores for each group were calculated as shown in Table I.

TABLE I.

TEST RESULTS FOR EXPERIMENTAL AND CONTROL GROUPS

\begin{tabular}{|c|c|c|c|c|c|}
\hline \multirow{2}{*}{ Group } & \multicolumn{2}{|c|}{ Pretest } & \multicolumn{2}{c|}{ Posttest } & \multirow{2}{*}{ Difference } \\
\cline { 2 - 5 } & Average & S.D. & Average & S.D. & \\
\hline Control & 68.06 & 11.96 & 76.29 & 9.32 & 8.23 \\
\hline Experimental & 70.00 & 12.93 & 82.88 & 9.45 & 12.88 \\
\hline
\end{tabular}

The Levene test was conducted for the equality of variance to verify that both groups had the same properties. The statistical results showed standard deviation of two groups were the same $(F=1.445, p=0.232>0.05)$. Similarly, homogeneity of with-group regression slopes was examined. The results showed the regression slopes for these two groups were similar $(\mathrm{F}=1.360, \mathrm{p}=0.246>0.05)$. Therefore, test scores can be analyzed by ANCOVA. According to statistical results, a significant difference was found between the experimental group and control group $(\mathrm{F}=139.595, \mathrm{p}=0.000<0.05)$. One conclusion was reached that Web3D application of automatic weather station was effective to improve training quality. In other words, Web3D training has obvious strengths in achieving higher training quality and better practical effects compared to traditional mode.

\section{CONCLUSION}

This paper bases on a Web3D application in the training of automatic weather station in China. It describes how to create the practical and efficient Web3D virtual training from theory analysis to system implementation.Web3D technical advantages are worth digging deeper, which helps trainees to enhance their practical capacities. Also, three virtual training methods are summarized to offer actual guidance on Web3D training application. Principles and essential operations of specialized instrument are carefully designed and simulated in details, which achieves better training effects and survey results.

\section{REFERENCES}

[1] China Meteorological Administration, Surface weather observation specification, Beijing, China: Meteorological Press, 2007, pp. 105-110.

[2] Jiang Xue Cui, Surface weather observation, Beijing, China: Meteorological Press, 2011, pp. 271-295.

[3] Hu Wen, Equipment support of basic automatic weather station, Beijing, China: Meteorological Press, 2013, pp. 36-230.

[4] Luca Chittaro, Roberto Ranon, "Web3D technologies in learning, education and training: Motivations, issues, opportunities," Computers \& Education, vol. 49, no. 1, pp. 3-18, 2007. http://dx.doi.org/10.1016/j.compedu.2005.06.002

[5] Nigel W. John, "The impact of Web3D technologies on medical education and training," Computers \& Education, vol. 49, no. 1, pp. 19-31, 2007. http://dx.doi.org/10.1016/j.compedu.2005.06.003

[6] Hui Yu Yang, Hao Zhang, Wei Xu, Ping Jian Zhang, Liang Ming Xu, "The Application of KINECT Motion Sensing Technology in Game-Oriented Study," International Journal of Emerging Technologies in Learning, vol. 9, no. 2, pp. 59-63, 2014. http://dx.doi.org/10.3991/ijet.v9i2.3282

[7] Grigore Burdea, Philippe Coiffet, "Virtual Reality Technology," Teleoperators and Virtual Environments - Presence, vol. 12, no. 6, pp. 663-664, 2003.

[8] Teresa Monahan, Gavin Mcardle, Michela Bertolotto, "Virtual reality for collaborative e-learning," Computers \& Education, vol. 50, no. 4, pp. 1339-1353, 2008. http://dx.doi.org/10.1016/j.compedu.2006.12.008

[9] Abdul-Hadi Ghazi Abulrub, Alex Attridge, Mark A Williams, "Virtual Reality in Engineering Education: The Future of Creative Learning," International Journal of Emerging Technologies in Learning, vol. 6, no. 4, pp. 4-11, 2011.

[10] Li Xiaobo, "Dynamic display of the fracturing process based on Web_3D," Electronic Test, no. 3, pp. 36-39, 2014.

[11] Liu Zhaoshu, Li Gangyan, Zhu LiIi, "Development on fabric interactive design module for auto-inner decoration," Modern Manufacturing Engineering, no. 9, pp. 67-69, 2006.

[12] Meng Yong-don, Tian Bin, Liu De-fu, "Study on application of Visual simulation for hydraulic engineering construction based on Web3D technology," Water Power, vol. 30, no. 7, pp. 22-25, 2004.

[13] Han Lina, Zhang Xufans, Ma Bin, "Deposit 3D visualization system based on Web3D technology and its application," Gold, vol. 30 , no. 5 , pp. 29-33, 2009.

\section{AUTHORS}

Rui Yang is with the China Meteorological Administration Training Centre, China Meteorological Administration, Beijing, P.R. China (yangr@cma.gov.cn).

WenJie Fan is with the China Meteorological Administration Training Centre, China Meteorological Administration, Beijing, P.R. China (fanwj@cma.gov.cn).

Jingrong Sun is with the China Meteorological Administration Training Centre, China Meteorological Administration, Beijing, P.R. China (sunjr@cma.gov.cn).

Submitted, 16 April 2015. Published as resubmitted by the authors on 19 May 2015. 